\title{
Air pollutants and their degradation of a historic building in the largest metropolitan area in Latin America
}

Authors: Marcos L.S. Oliveira, Alcindo Neckel, Diana Pinto, Laercio Stolfo Maculan, Matheus Roberto Dalmagro Zanchett, Luis F.O. Silva

\begin{abstract}
:
Historic buildings that comprise the cultural heritage of humanity are in need of preservation on a worldwide scale in regard to degradation resultant from atmospheric pollutants. The Brazilian Public Market, located in the historic center of the mega city of Sao Paulo, is the object of this research, due to its representation of historical Brazilian architecture. The general objective of this manuscript is to analyze the influence of air pollutants on the degradation of the historic Sao Paulo Public Market in the city of Sao Paulo, Brazil. Methodologically, between May 2018 and April 2019, samples of sedimented dust were collected at five points on the side walls of the market's historic structure, for the analysis of accumulated ultrafine particles (UFPs) and nanoparticles (NPs). A total of 20 samples of particulate matter were collected using self-made passive samplers (SMPSs). Using SMPSs, 12 months of accumulation and deposition were used to sample the atmospheric $\mathrm{PM} 1$. The results demonstrate the presence of dangerous elements such as: $\mathrm{As}, \mathrm{Cd}, \mathrm{Cr}, \mathrm{Pb}, \mathrm{Zn}$. Note that EDS coupled with microscopy techniques, points out the risks to human health, due to the presence of these dangerous elements that accumulate in the building's structure. The results show that $85 \%$ of the NPs sampled contained $\mathrm{Pb}$, and $56 \%$ contained $\mathrm{Pb}$ and $\mathrm{Ti}$, which are harmful to both historic buildings and human health. Air pollution enables the further deterioration of the Sao Paulo Public Market, which is in need of restoration.
\end{abstract}

Keywords:

Vehicular traffic, Industrial pollutants, Built historical heritage, Nanoparticles, Toxic elements, Human health

DOI: https://doi.org/10.1016/j.chemosphere.2021.130286 